\title{
Building the glycolisis and Krebs cycle as a puzzle: a strategy to learning metabolic pathways.
}

Lazarim, F.L.; Catanho, F.O.S.; Tessutti, L.S.; Hohl, R.; Machado, E.; Ferrucci, D.; Lourenço, T.; Passos, M.A.; Buscariolli, R.; Normand, A.C.; Ferraresso, R.L.P.; Sarraipa, M.; Trape, A.; Gonçalves, M. C. A. and Macedo, D.V.

Laboratório de Bioquímica do Exercício LABEX, Departamento de Bioquímica, Instituto de Biologia UNICAMP, Campinas São Paulo Brasil

First year physical education students must understand metabolic pathways to know how our body produces energy during exercise of different intensities and rest. However, in a first contact they usually complain about the difficulty to understand and visualize all the process such as the sequence of reactions, the structure of the molecules and mainly what is changing in the molecule. In an attempt to make easier the comprehension of the metabolic pathways we make a puzzle in a classroom where the students have to build the glicolysis and Krebs cycle through some clues given to guide them to organize the sequence of reactions. For this, the students were divided in groups of four and each one received figures with the structural formula of the molecules and their names. The groups that were changing in the structure were colored. The clues included information such as the compound that begins the pathway and its final product, number and kind of enzymes involved, number of ATPs produced, reactions with negative energy variation and number of compounds rich in energy produced. The students have no difficulty to visualize the structures or building these pathways. After that, they have some questions to answer to see if they understand and learned the pathway. They reported that is easier to understand what is changing and why, making the comprehension of what is occurring during exercise easier and have no difficulties to discuss and answer the questionnaire. 